\title{
O campo das Ciências Criminais e suas sociologias inventadas
}

\author{
José Antônio Gerzson Linck ${ }^{1}$
}

\begin{abstract}
Resumo
$\mathrm{O}$ artigo problematiza o sentimento de perplexidade do personagem do livro $\mathrm{O}$ Processo, de Franz Kafka, ao perceber o funcionamento da malha jurídica, apresentando possibilidades de pesquisas criminológico/etnográficas de manifestações contemporâneas que exaltam a mesma perturbação no contato com os dispositivos jurídicos.
\end{abstract}

\begin{abstract}
The article discusses the feeling of perplexity of character in the book by Franz Kafka, to understand the functioning of the legal mesh, presenting possibilities of criminological/ethnographic research contemporary manifestations of the same disorder that exalt in contact with the legal provisions.
\end{abstract}

\section{O absurdo estético como representação da concretude do real.}

No dia seguinte, ao meio-dia, a gente estava almoçando, o cara chegou com mais dois. Apertou a mão do Nélio, deu um abraço nele e, enquanto abraçava, meteu a mão na pistola, deu dois passos para trás e disparou quatro tiros. Nélio ficou sangrando que nem porco. Até morrer. Eu me lembro que ainda pensei: "Dois reais, porra. Dois reais." Aquilo não me saía da cabeça, enquanto meu amigo agonizava ${ }^{2}$.

Nas Faculdades de Direito, nada mais comum que a designação de um processo judicial como kafkiano, a adjetivação de uma situação como kafkiana ou uma mudança legislativa como a prova da inabilidade dos legisladores que insistem em criar leis kafkianas. Como se Kafka fosse um burocrata mal humorado que reuniu suas insatisfações jurídicas em um manifesto chamado $O$ Processo, no claro intuito de que juristas letrados e bem intencionados transformassem o caos burocrático em um paraíso de ordem e previsibilidade. O absurdo do livro O Processo não é absurdo por ser uma situação fora do comum, impossível

\footnotetext{
${ }^{1}$ Doutorando em Ciências Criminais, Professor Universitário.

${ }^{2}$ SOARES, Luiz Eduardo [et al].Cabeça de Porco. Rio de Janeiro: Objetiva, 2005, p.114.
} 
de acontecer ou mágica. O absurdo fático não é menos concreto se representado como absurdo literário.

$\mathrm{O}$ artigo problematiza o sentimento de perplexidade do personagem do livro $\mathrm{O}$ Processo, de Franz Kafka, ao perceber que o absurdo da estrutura do Estado de Direito e suas instituições liberais não são um defeito do sistema jurídico, mas sua rede de sustentação. $\mathrm{O}$ intuito é provocar diálogo entre a percepção do absurdo que o personagem expõe ao perceber o funcionamento da malha jurídica e possibilidades de pesquisas etnográficas de manifestações contemporâneas que exaltam a mesma perturbação no contato com os dispositivos jurídicos.

\begin{abstract}
Não há dúvida de que por trás de todas as manifestações deste tribunal, no meu caso por trás da detenção e do inquérito de hoje, se encontra uma grande organização. Uma organização que mobiliza não só guardas corrompíveis, inspetores e juízes de instrução pueris, no melhor dos casos simplórios, mas que, além disso, de qualquer modo, sustenta uma magistratura de grau elevado e superior, com o seu séquito inumerável e inevitável de contínuos, escriturários, gendarmes e outros auxiliares, talvez até de carrascos, não recuo diante dessa palavra. E que sentido tem essa grande organização, meus senhores? Consiste em prender pessoas inocentes e mover contra elas processos absurdos e na maioria da vezes infrutíferos, como no meu caso.Diante dessa falta de sentido do conjunto, como evitar a pior das corrupções entre os funcionários? É impossível, nem o supremo magistrado teria êxito. É por isso que guardas tentam roubar a roupa do corpo dos detidos, é por isso que inspetores invadem casas alheias, é por isso que inocentes devem ser aviltados diante de assembleias inteiras ${ }^{3}$.
\end{abstract}

Quando sentamos nos bancos escolares das faculdades de direito, na espera impossível de uma iluminação vinda do púlpito, não sabemos muito bem o vínculo entre o que iremos aprender e a realidade concreta das coisas. Esta afirmação não nega toda a importância do relativismo, mas é necessário ter cuidado com a aparência das palavras. Existe uma realidade concreta: corpos com órgãos vivos e funcionando dentro de jaulas. Jaulas construídas para humanos, legitimadas por discursos que as apoiam, mas legitimadas também por discursos que, supostamente, as criticam.

No campo das Ciências Criminais, a legitimação da política criminal (qualquer política criminal que não envolva a diminuição dos poderes do advogado em White Collar Crimes, por evidente) é escandalosa. Se a criminalização primária (criação das leis) é impossível de ser satisfeita pela repressão secundária, é transparente a necessidade de selecionar dentre todos que cometem delitos uma porção insignificante que possa legitimar o fundamento do poder punitivo.

\footnotetext{
${ }^{3}$ KAFKA, Franz. O Processo. São Paulo: Companhia das Letras, 2005, p.47.
} 
Por mais que os brasileiros, sobretudo os juristas, de fato acreditem que são brancos, descendentes diretos e nunca miscigenados desde que seus primeiros conterrâneos pisaram no solo brasileiro, isso não seria motivo suficiente para desconsiderarem que o sistema penal brasileiro é racista e genocida. Se qualquer acadêmico possui obrigação de saber que em seu próprio país a dinâmica punitivista é direcionada em primeiro lugar para o preto, fica complicado entender porque isto não é mencionado nos livros de direito penal, como se questões não relacionadas aos aspectos factuais devessem ficar restritas ao campo criminológico. Algo como dizer que os processualistas e os penalistas seriam para as ciências criminais o que os cineastas de ficção científica representam no campo cinematográfico: Deixem os documentários para os criminólogos, pois a utilização de terno e gravata deve obstar qualquer fundamentação que não seja baseada na sociologia fantástica do penalismo alucinado.

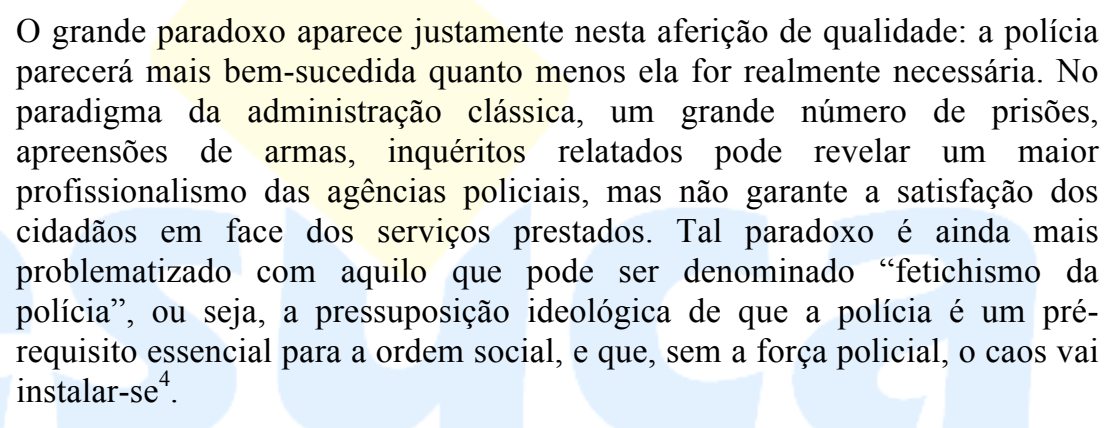

As disciplinas propedêuticas que deveriam trazer o acadêmico para a reflexão da vida concreta são considerados apenas pré-requisitos, testes pelos quais se deve passar no intuito de, enfim, aprender (reproduzir) Direito. Se 99\% dos presos brasileiros ganharem menos de um salário mínimo, este não será um tema suficientemente jurídico para ser estudado, mas uma questão sociológica ou no máximo algo relegado à Criminologia. Os princípios do direito penal tornam-se, assim, a reprodução não-reflexiva de ideias liberais absolutamente desvinculadas de qualquer arsenal fático. O que explica os arroubos da advocacia e dos estudantes de direito com julgamentos como o mensalão, o que não acontece nas frequentes chacinas e extermínios cometidos pela polícia e legitimados pelo poder punitivo.

Se o poder punitivo só pode trabalhar através de uma seleção prévia de inúmeras condutas criminalizáveis; se no Brasil esta seleção possui raça e classe social específicas; se tais obviedades podem ser observadas em qualquer estatística penitenciária e se o movimento ocorrido após a democratização foi no mesmo sentido histórico da escravidão, resta saber

\footnotetext{
${ }^{4}$ BATISTA, Vera Malaguti. Paz Armada. Rio de janeiro; Revan, 2012, p.38.
} 
porque não é preciso fazer uma pesquisa para descobrir o índice de acadêmicos brasileiros que já ouviram falar em Florestan Fernandes, Gilberto Freyre, Roberto da Matta ou Sérgio Buarque de Holanda. Todo ano o país fica espantado com a superlotação carcerária deste ou daquele presídio, com situações como o confinamento da menina menor de idade em um presídio para adultos do sexo masculino (sendo estuprada reiteradas vezes por pessoas diferentes em dias consecutivos) ou com o assassinato por engano de um estudante negro que estava indo para casa e foi alvejado por uma polícia pacificadora.

\begin{abstract}
Enquanto o esquema do preconceito racial norte-americano é de "origem", o brasileiro é de "marca". Ou seja: o sistema americano não admite gradações e tem uma forma de aplicação axiomática: uma vez que se tenha algum "sangue negro" (e isso é determinado culturalmente), não se pode mudar jamais de posição. Pode-se ser tratado idealmente como um "igual perante a lei", mas a diferença do "sangue" permanecerá para sempre. Já no nosso sistema, o ponto-chave é a admissão de gradações e nuanças. A "raça"(ou a cor da pele, o tipo de cabelos, de lábios, do próprio corpo como um todo etc.) não é o elemento exclusivo na classificação social da pessoa. Existem outros critérios que podem nuançar e modificar essa classificação pelas diferenças físicas (que são definidas culturalmente). Assim, por exemplo, o dinheiro ou o poder político permite classificar um preto como mulato ou até mesmo como branco. Como se o peso de um elemento (como o poder econômico) pudesse apagar o outro fator. Temos, pois, no Brasil, sistemas múltiplos de classificação social; ao passo que nos Estados Unidos há uma tendência nítida para a classificação única, tipo "ou tudo ou nada", direta e dualista, tendência que me parece estar em clara correlação com o individualismo, o igualitarismo e a ética protestante 5 .
\end{abstract}

Tais fatos são tratados pelos juristas da mesma forma com que estes tratam a obra $\mathrm{O}$ Processo: erros pontuais a serem corrigidos com a figura inesquecível do Progresso, exalando a linearidade típica dos processos de auto-legitimação. Se O Processo não representar uma burocracia em frangalhos - a ser transformada em um império da boa justiça - e sim a realidade fática e impossível de ser corrigida com os vernáculos generosos do academicismo de terno e gravata, como legitimar sua atuação como jurista? Se for exposta a manutenção da artilharia estatal contra as mesmas classes e raças de sempre, como fundamentar a pena no estado brasileiro? Melhor esquecer tudo isso, deixar estes assuntos menos dogmáticos para sociólogos e manter a boa consciência dos Bacharéis absolutamente intocada. Infelizmente, se a vida não é percebida como guerra no universo jurídico, ela não deixa de sê-lo na realidade concreta do cotidiano.

A percepção da vida como guerra. A vida é uma guerra, mas não porque é difícil vivê-la. Não se trata somente das dificuldades das pessoas para sobreviver e vencer a pobreza.Pensar a vida como guerra é uma maneira de

\footnotetext{
${ }^{5}$ DaMatta, Roberto. Relativizando. São Paulo: Rocco, 2012, p.90.
} 
conferir inteligibilidade a todas as relações sociais a partir da ideia do conflito e do enfrentamento.São múltiplos os conflitos que organizam a vida: entre brancos e negros, entre ricos e pobres, com a polícia, com o Estado, com a ideia de sistema, mas também entre homens e mulheres ou entre os pobres, com tipos sociais como o Zé Povinho ou o verme, que voltaremos a discutir mais adiante. A guerra cotidiana é uma maneira de compreender o que se passa no interior do corpo social, portanto a guerra é entendida como relação social permanente. Por outro lado, a paz é uma utopia desejada, mas considerada quase impossível.A paz habita o terreno do sonho ou do desejo inatingível, nunca é uma percepção da realidade ${ }^{6}$. P. 193 saídas de emergência.

Entre numerosas corporificações da sujeira capazes de minarem padrões é de especial importância aquele em que seres humanos são concebidos como um obstáculo à organização do ambiente, estimulando dinâmica segregacionista no arranjo estético urbano, de forma semelhante às metáforas ecológicas do social: a cultura homogênea só faz sentido supondo como mais natural a inclusão de certos valores do que outros, supondo que a pureza dos compostos é característica dos ingredientes, não a maneira como foram classificados ${ }^{7}$.

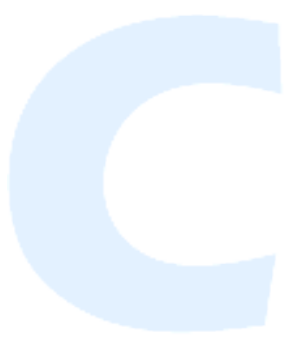

Partindo da premissa que a democracia tem por base uma igualdade, estruturada na naturalização do indivíduo, constituída pelo direito, o que pressupõe a exclusão do desigual (diferente) em nome da ordem, cabe aqui lembrar que nesse caso a força política se sustenta na medida em que se purifica, colocando a distância entre a ordem e a desordem, a pureza e o perigo, com a tentativa de eliminação do estranho, do desigual, impedindo que ele se torne um perigo ameaçador da homogeneidade ${ }^{8}$.

O fenômeno da produção da pureza - como o do etiquetamento do desvio - põe um problema de ordem epistemológica: é impossível delimitá-lo face à hiperescolha que existe, das fronteiras mais estreitas aos horizontes mais vastos ${ }^{9}$. Tais fenômenos também podem assumir reagrupamentos, face à extensão das novas configurações dos fenômenos sociais contidos no desvio ou na exclusão ${ }^{10}$.Quem quiser propor a forma de uma nova sociedade urbana fortificando esse germe - o urbano - que se mantém nas fissuras da ordem planificada e programada, deve ir mais longe ${ }^{11}$. A exclusão e o etiquetamento podem ser justificados por conjunções culturais nas quais se coloca um sinal negativo, mas também podem motivar aglomerações sociais através da transformação do conteúdo negativo da etiqueta em forma de pertencimento comunitário ou construção identitária.

\footnotetext{
${ }^{6}$ CABANES, Robert [et al].Saídas de Emergência.São Paulo: Boitempo, 2011, p.193.

${ }^{7}$ BAUMAN, Zygmunt. Em busca da política. Rio de Janeiro: Jorge Zahar, 2000, p.202.

${ }^{8}$ GAUER, Ruth M.Chittó. Da Diferença Perigosa ao Perigo da Igualdade. Porto Alegre: Civitas, v.5. n 2. 2005. p. 402.

${ }^{9}$ XIBERRAS, Martine. As Teorias da Exclusão. Lisboa: Piaget, 1994. p.22.

${ }^{10}$ XIBERRAS, Martine. As Teorias da Exclusão. Lisboa: Piaget, 1994. p.23.

${ }^{11}$ LEFEBVRE, Henri. $O$ direito à cidade. São Paulo: Centauro, 2001, p.85.
} 
Martine Xiberras compreende que a ritualização de algumas práticas contemporâneas contidas em grupos, festas e espaços de socialidade servem como alegorias de união ${ }^{12}$ de grupos normativo ou culturalmente rechaçados pelo empresariado moral ${ }^{13}$. A antropóloga sustenta que alguns grupos contemporâneos perecem de metanóia, espécie de enfermidade social que contamina os movimentos vanguardistas, quando uma série de ideias e ações conexas não adquirem unidade discursiva. Ainda que não se afirmem como um discurso consistente, nem por isso deixam de propor uma concepção de conexão social que realizam no próprio ato das práticas coletivas.

Por mais submersas que possam parecer, estas coletividades desenvolvem-se em várias zonas das nossas sociedades, representando micro-comunidades relativamente coesas e, ao mesmo tempo, plurais $^{14}$. A multiplicidade, facilitada pelo enfraquecimento de grandes referências, deixa espaço para identificações abertas e improváveis para uma leitura conceitualmente mais rígida.

Processo que não chega a ser contraditório ou antagônico, já que possui diversas variáveis, mas que aqui é tensionado como forma argumentativa: a presença de um controle segregacionista que transcende o poder estatal - fixando-se em diversos ponto da malha cultural - e a irrupção concomitante de performances juvenis de utilização/ocupação/reterritorialização de espaços públicos onde o exercício da cidadania é direcionado para o encontro, para a negação da propriedade da rua, para a negação da formalização vertical de condutas e apostando na diversidade, na interação e na ética do instante como forma libertária de segurança: a fusão de horizontes pode se transformar num projeto um pouco mais realista se buscarmos concretizá-la (mesmo que por tentativa e erro, e com êxito apenas relativo) nas ruas da cidade ${ }^{15}$.

A sociedade urbana e o urbano persistem e mesmo se intensificam. As relações sociais continuam a se tornar mais complexas, a se multiplicar, a se intensificar, através das contradições mais dolorosas. A forma do urbano, sua razão suprema, a saber a simultaneidade e o encontro, não podem desaparecer. A realidade urbana, no próprio âmago de sua deslocação, persiste e se densifica nos centros de decisão e de informação. Os habitantes (quais? Cabe às pesquisas e aos pesquisadores encontrálos!) reconstituem centros, utilizam certos locais a fim de restituir, ainda que irrisoriamente, os encontros. O uso (o valor de uso) dos lugares, dos monumentos, das diferenças, escapa às exigências da troca, do valor de troca ${ }^{16}$.

\footnotetext{
${ }^{12}$ XIBERRAS, Martine. A Sociedade Intoxicada. Lisboa: Piaget, 1989. p.194.

${ }^{13}$ BECKER, Howard. Outsiders: estudos de sociologia do desvio.Rio de Janeiro: Zahar, 2008, p.22.

${ }^{14}$ XIBERRAS, Martine. A Sociedade Intoxicada. Lisboa: Piaget, 1989. p.197.

1515 BAUMAN, Zygmunt. Amor líquido: sobre a fragilidade dos laços humanos. Rio de Janeiro: Jorge Zahar, 2004, p.141.

${ }^{16}$ LEFEBVRE, Henri. $O$ direito à cidade. São Paulo: Centauro, 2001, p.85.
} 
Tanto nos espaços centrais da cidade, como nos espaços periféricos ou boêmios cada vez mais é o oficial de plantão da polícia ou algum secretário administrativo imbuído de mesmo poder que decide se vai haver festa ou baile funk $k^{17}$.

\begin{abstract}
A aceitação da inevitabilidade da sociedade do risco, dominada pela racionalidade econômica, implica em gerenciar a criminalidade com técnicas de gestão atuarial. No âmbito criminológico, se abandonada a idéia de que a delinquência existe como conseqüência de determinadas privações ou problemas sociais. No âmbito da política criminal, o atuarialismo considera que os conceitos econômicos básicos, como racionalidade, maximização, custos e benefícios, etc., são fundamentais para entender, explicar e combater de maneira efetiva a atividade criminal. As políticas neo-conservadoras de combate ao delito tem como principal objetivo a dissuasão do delinqüente, mediante a modificação do preço do delito, ou a sua pura e simples contenção. Se trata de encontrar políticas de otimização da relação custo benefício do combate ao crime, com o mínimo custo possível para o Estado ${ }^{18}$.
\end{abstract}

Possível afirmar, como Becker ${ }^{19}$, que o desvio depende da reação da cruzada moral para que receba, então, a substância contida na etiqueta: seria exclusivamente produção do empresariado probo e fervoroso da moral. Possível questionar essa afirmação, afinal muitas vezes a tentativa de etiquetamento chega tão tarde que os desviantes já se consideravam, de alguma forma, estranhos - fora do lugar. Por outro lado, a etiqueta pode ser o resultado de normas sociais não necessariamente formalizadas, respaldando o pensamento do autor e dialogando com a afirmação de Delmas-Marty:

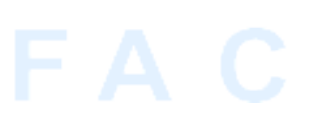

O desvio remete à norma social e remonta à normalização. Ele situa-se portanto num campo de normalidade no qual o poder que dita a norma é mais difuso, atomizado, móvel, difícil de ser circunscrito: um poder sem um centro, sem uma localização específica e mais frequentemente invisível (família, escola, igreja, clube, ambiente profissional, etc). O desvio aparece mais como não-conformidade com a norma do que como incompatibilidade. Trata-se, portanto, de um comportamento em si mesmo difuso, menos nitidamente delimitado: é mais um estado com certa duração do que uma ação ou omissão de caráter instantâneo ${ }^{20}$.

Há um problema epistemológico que complexifica o tema e sugere ampliação do campo: a capacidade de compreensão do censor não alcança a totalidade dos significados de algumas condutas: Desta forma, a própria resposta ao estado de não-conformidade será

\footnotetext{
${ }^{17}$ BATISTA, Vera Malaguti. Introdução crítica à criminologia brasileira. Rio de janeiro: Revan, 2011, p.99.

${ }^{18}$ AZEVEDO, Rodrigo Ghiringhelli de. Visões da Sociedade Punitiva: Elementos para uma Sociologia do Controle Penal; in GAUER, Ruth M. Chittó (org.). Sistema Penal e Violência. Rio de Janeiro: Lumen Juris, 2006. p. 59.

${ }^{19}$ BECKER, Howard. Outsiders: estudos de sociologia do desvio.Rio de Janeiro: Zahar, 2008, p.155.

${ }^{20}$ DELMAS-MARTY, Mireille. A imprecisão do Direito: do Código penal aos Direitos Humanos. Barueri: Manole, 2005, p.114.
} 
difusa, evocando mais um processo de segregação do que o instante da troca (desviocastigo). Não uma sanção descontínua, mas uma normalização quase contínua ${ }^{21}$ :

\begin{abstract}
$\mathrm{O}$ poder estatal concede às suas instituições funções manifestas, que são expressas, declaradas e públicas.Trata-se de uma necessidade republicana; um poder orientador que não expresse para que é exercido não pode submeter-se ao juízo de racionalidade. Porém, em geral, essa função manifesta não coincide por completo com o que a instituição realiza na sociedade, ou seja, com suas funções latentes ou reais.Tal disparidade deve ser sempre objeto de crítica institucional, porque é a única maneira de controlar a racionalidade do poder, pois, em caso contrário (se a discussão se mantiver ao mero nível das funções manifestas), o controle seria de pura racionalidade do discurso.O poder estatal com função manifesta não-punitiva e funções latentes punitivas (ou seja, que não exprime discursivamente suas funções reais) é muito mais amplo do que aquele que ostensivamente tem a seu cargo as funções punitivas manifestas ${ }^{22}$.
\end{abstract}

\title{
2. Narrativas do absurdo: Criminologias e etnografias contemporâneas
}

Em um pequeno artigo derivado da transcrição de uma palestra no programa de pósgraduação em antropologia social do museu nacional (UFRJ), Howard Becker expõe a imensa multiplicidade teórica das gerações que o antecederam na Escola de Chicago e, mais ainda, nas Escolas de Chicago que se multiplicaram por diversas outras cidades, americanas ou não. Refere, também, que a principal característica da escola era pensadores com ideias diferentes dispostos a fazer um mesmo tipo de atividade científica: empírica, com grau variável de interacionismo.

Preocupada, assim, com as questões da vida cotidiana que passam despercebidas por grandes sistemas de explicação do mundo e, portanto, diferente das escolas de pensamento onde pesquisadores em locais próximos ou distantes comungam de mesma matriz teórica (o que normalmente acaba se verificando apenas muitos anos depois).

Não há como descrever a escola de Chicago, possível apenas ressaltar que foi a fonte criativa para os primeiros trabalhos de antropologia urbana do museu nacional da UFRJ e vários outros centros de pesquisa na temática desenvolvidos no país, além da importância que investigações como Outsiders de Howard Becker tiveram no campo criminológico.

Gilberto Velho na apresentação da edição brasileira de Os Estabelecidos e os Outsiders de Norbert Elias refere que um dos principais focos da produção da Escola de

\footnotetext{
${ }^{21}$ DELMAS-MARTY, Mireille. A imprecisão do Direito: do Código penal aos Direitos Humanos. Barueri: Manole, 2005, p.114.

${ }^{22}$ ZAFFARONI, E. Raul; BATISTA,Nilo; ALAgIA, Alejandro; SLOKAR, Alejandro. Direito Penal Brasileiro: Teoria Geral do Direito Penal. Rio de Janeiro: Revan, 2 ed.,2003, p.88.
} 
Chicago é a temática indivíduo e sociedade, sobretudo os contrastes e continuidades entre a interação de grupos e as estruturas sociais mais amplas ${ }^{23}$.

Não podemos pensar na Escola de Chicago como um grupo homogêneo pela variedade temática de seus autores, mas a presença da transdisciplinaridade e a importância atribuída à interação (relações entre grupos e sujeitos ativos dentro de malhas sociais móveis - e não como mônadas isoladas) opõem-se aos modelos estáticos onde a mudança social é sempre contrastada e problematizada através do espelhamento à padrões sociais e estruturas predefinidas.

Whyte $^{24}$ define por diversas vezes seu trabalho como observação participante e seu objetivo como um fronte contra a sustentação de políticas públicas arbitrárias e truculentas.O autor expõe as dificuldades que enfrentou para que seu trabalho fosse encarado como uma tese de doutorado, já que se negou a começar com a tradicional revisão de literatura sobre o campo (no caso, o Distrito de Corneville) ou terminar explicitando a contribuição de seu trabalho para futuras pesquisas na área temática. Após um membro da banca insistir na inexistência de categorias conceituais sobre áreas urbanas degradadas, Whyte respondeu simplesmente que achava desnecessário citar todas as pesquisas sobre o assunto, sobretudo porque a grande maioria delas era apenas revisão da anterior.

Acabou aceitando fazer uma revisão de literatura sobre o assunto, mas se negou a incorporá-la na tese. $\mathrm{O}$ fato demonstra que não só no Brasil, como refere Magnani ${ }^{25}$, os trabalhos em contato com a antropologia urbana tiveram dificuldade para serem aceitos como acadêmicos. Posteriormente, Whyte insistiu na radicalização da interação do pesquisador: anexou ao livro seus envolvimentos em crimes federais durante a pesquisa, tentativas frustradas de seduzir garotas nos bares de Cornerville e toda espécie de erros que refere terem acrescentado tanto para a temática quanto os livros que havia lido ${ }^{26}$.

Autores de campos diferentes de saber tentaram criar categorias flexíveis para mapear a relação entre a autonomia pessoal e as relações de força e proximidade que influenciam as construções identitárias (sempre múltiplas, complexas, irredutíveis). Podemos citar os campos identificatórios de Maria Rita Kehl, os campos de possibilidades de Gilberto Velho, a relação

\footnotetext{
${ }^{23}$ ELIAS, Norbert. Os estabelecidos e os outsiders: sociologia das relações de poder a partir de uma pequena comunidade. Rio de Janeiro, Zahar, 2000, p.11.

${ }^{24}$ WHYTE, William Foote. Sociedade de esquina: a estrutura social de uma área urbana pobre e degradada. Rio de Janeiro: Jorge Zahar, 2005, p.347.

${ }^{25}$ MAGNANI, José Guilherme Cantor. Jovens na metrópole. São Paulo: Terceiro Nome, 2007, p.253.

26 WHYTE, William Foote. Sociedade de esquina: a estrutura social de uma área urbana pobre e degradada. Rio de Janeiro: Jorge Zahar, 2005, p.352.
} 
entre socialização primária e socialização secundária no clássico trabalho de Berger e Luckman (A construção social da realidade), os processos de singularização de Félix Guattari (Micropolítica: cartografias do desejo) ou o modus vivendi interacional de Goffman em $A$ Representação do Eu na vida cotidiana.

Importante ressaltar que o visível crescimento da complexidade nas grandes cidades não torna o trabalho da antropologia urbana uma espécie de coleção de relatos confusos e impossíveis de relação entre si pela infinitude da tarefa etnográfica, o que tornaria o antropólogo urbano espécie de colecionador de objetos inesgotáveis. A mesma crítica poderia ser feita a trabalhos meramente teóricos cuja veracidade igualmente pode ser posta à prova com outro referencial bibliográfico, infinitamente.

O estudo contínuo de grupos ou tribos urbanas pode salientar as mudanças e continuidades de formas de existência que não podem ser desconsideradas na análise das tentativas de controle urbano, sobretudo as intituladas criminologias da vida cotidiana. A etnografia, porém, também não é a veracidade do cotidiano. Objetividade e subjetividade ou teoria e empiria nas ciências humanas não deveriam representar uma oposição valorativa, mas uma possibilidade de conjunção.

\begin{abstract}
O cuidado principal parece ser o de não confundir a construção das características comuns, que são ideais, derivadas das regras de experiência social dos cursos de ação comuns a vários indivíduos, com forças e agentes reais, como também não permitir que essa construção se enviese ao incorporar perspectivas normativas e juízos de valor implícitos, unilaterais, no recorte das características. Evidentemente isso não é fácil, mas o tipo social não precisa ser complexo, como são os homens reais, apenas é preciso que ele seja mais complexo que o tipo empírico e menos unilateral e mais real que o tipo ideal. Os tipos sociais existem na representação social, exprimem relações sociais e podem ser diretamente derivados daí quando se está nesse plano da análise. Certos estereótipos se prestam, com maior facilidade, para a construção social dos tipos. Compreendidos como pertencentes ao objeto e não como instrumentos de análise ou tipos ideais, os tipos sociais podem ser úteis à análise por reunirem e condensarem em indivíduos o que pertence ao nível das diferenças nas relações sociais e nos modos e estilos de operar o poder por diferentes grupos $^{27}$.
\end{abstract}

Dois artigos publicados no livro A Aventura Sociológica - organizado por Edson de Oliveira Nunes - são interessantes para refletir sobre o problema proposto. Roberto da Matta (Sobre o ofício de ser etnólogo ou como ter anthropological blues) e Gilberto velho (Observando o familiar) polemizam sobre supostas diferenças entre fazer antropologia do exótico e antropologia do familiar. $O$ primeiro ressalta que existem três etapas na

\footnotetext{
${ }^{27}$ MISSE, Michel. Malandros, marginais e vagabundos. A acumulação social da violência no Rio de janeiro. Tese de Doutorado em Sociologia: IUPERJ, Brasil, 1999,p.254.
} 
consolidação de um trabalho de campo sobre o exótico: representá-lo em um nível teórico, preparar a chegada ao campo e por fim tornar o exótico familiar.

$\mathrm{Na}$ antropologia urbana a tentativa seria inversa - estranhar o familiar. Gilberto Velho complexifica a relação familiar/exótico, afirmando que moradores de um mesmo prédio podem ter menos afinidade e conhecimento entre si do que com um morador das Antilhas ou da Nicarágua e que, portanto, não é a distância física que torna o outro familiar ou exótico.

Desnecessário reanimar a antiga discussão sobre a necessidade de separação entre sujeito e objeto, visto que a autoneutralização da sedução alheia é sempre uma suposição. Objetificamos a nós mesmos cada vez que procuramos formas de nos distanciar do objeto. $\mathrm{O}$ pesquisador não é espécie de xamã capaz de sair de si mesmo, olhar-se de cima e verificar o grau de proximidade com o outro, portanto este não é um problema a priori e sim algo que pode aparecer no trajeto da pesquisa e, neste caso, ser problematizado: Só pela evidenciação da estreita relação que liga esses dois termos, o real e o imaginário, espero desferir um novo golpe na distinção, que me parece cada vez mais mal fundamentada, entre subjetivo e objetivo $^{28}$.

O estudo Utopia Urbana, de Gilberto Velho, é considerado pioneiro na temática da antropologia urbana no Brasil. Procurando desfazer certa preocupação demasiado rígida entre o que seria uma investigação antropológica e uma investigação sociológica, o autor expõe já na introdução a importância de misturar diferentes tradições de trabalho. Sem isolar o objeto do contexto da cidade, Gilberto Velho estudou de forma intensiva moradores de um prédio de Copacabana onde ele, inclusive, havia residido. Longe de realizar uma antropologia do exótico, o autor faz longa explanação acerca da problemática de pesquisar o familiar, o próximo, aquilo que - apenas em tese - já seria conhecido ${ }^{29}$. O pesquisador é um dos precursores de uma série de pesquisas em antropologia urbana cujo referencial teórico dialoga intensamente com Howard Becker e Ervin Goffman.

Os filmes de Eduardo Coutinho, sobretudo Edifício Master, são outra espécie de fazer antropológico livre de uma metodologia rígida (embora possa haver certa intuição-expectativa antes das filmagens, ela não se coloca como hipótese, dada a ausência de um problema). É isto que torna o filme belo: a ausência de objetivo, exceto a beleza, favorece a captação da complexidade dos entrevistados, visto que as perguntas não são direcionadas. Não é possível

\footnotetext{
${ }^{28}$ MAFFESOLI, Michel. A violência totalitária. Porto Alegre: Sulina, 2001, p.310.

${ }^{29}$ VELHO, Gilberto. A utopia urbana: um estudo de antropologia social. Rio de janeiro: Zahar, 2010, p. 22
} 
fazer um trabalho acadêmico rigoroso desta forma, mas ela pode servir de inspiração e tentativa de estabelecer um método de conter o próprio rigor metodológico quando ele for excessivamente redutor.

Definições estanques acerca da identidade de grupos, assim como relações de interação e autoridade fixas, seriam pouco úteis como referencial para este trabalho, cuja temática envolve contatos bastante móveis e situações nas quais há bastante amplitude de apresentação das personas e, portanto, oferece uma multiplicidade de possibilidades de representação para o pesquisador: Não é certo que nossos gentis selvagens pós-modernos tenham em mente, em seus
transes musicais, esse arraigamento. Não há dúvida, em contrapartida, de que vivem,
concretamente, a importância do entorno. Sentem a necessidade do contexto para ser
o que são, pessoalmente, como portadores de máscaras, ou coletivamente, como
tribos, ao mesmo tempo, arraigadas e extáticas. Os territórios em que pisam e que
forjam, estruturam a realidade. Os territórios espaciais lhe dão uma existência
intensa, ou seja, no máximo do paradoxo, a saída de si no quadro de um território
leva a uma tensão imanente: a intensidade da comunidade efervescente, agitação na
vida em sua interidade, e agitação de vida. Eis o interesse do território: permite
comungar com o outro. Já não em função de um ideal distante, mas em referência a
valores vividos no presente. Ao mesmo tempo, teremos compreendido-o, esses
lugares que compartilhamos com outros permitem suavizar a carga trágica, ligada,
justamente, ao presenteísmo ${ }^{30}$.

Os projeto de segurança baseados na ordem urbana oferecem muito baixa probabilidade de sucesso para a função que manifestam (tornar a cidade noturna espécie de túmulo de pessoas vivas, onde se verificaria restrita quantidade de incivilidades, já que estariam desativadas pelo misto de tecnologias situacionais e tecnologias de persuasão midiática), mas podem ter função latente cujas consequências sejam importantes. Formulando com mais força: a experiência histórica sobre a maximização da segurança aponta direto para a ausência de liberdade: a liberdade morre com a segurança ${ }^{31}$. Sufocar a segurança com o exercício contínuo de liberdades parece ser característica desviante em tempos de aranoia securitária:

É um grande jogo que se está realizando sob os nossos olhos, com episódios diversos cujo sentido nem sempre aparece. A satisfação de necessidades elementares não consegue matar a insatisfação dos desejos fundamentais (ou do desejo fundamental). Ao mesmo tempo que lugar de encontros, convergência das comunicações e das informações, o urbano se torna aquilo que ele sempre foi: lugar do desejo, desequilíbrio permanente, sede da dissolução das normalidades e coações, momento do lúdico e do imprevisível ${ }^{32}$.

\footnotetext{
${ }^{30}$ MAFFESOLI, Michel. O instante eterno: o retorno do trágico nas sociedades pós-modernas. São Paulo: Zouk, 2003, p.187.

${ }^{31}$ ALBRECHT, Peter-Alexis. Criminologia: uma fundamentação para o Direito Penal. Rio de Janeiro: Lumen Juris, 2010, p.596.

${ }^{32}$ LEFEBVRE, Henri. O direito à cidade. São Paulo: Centauro, 2001, p.85.
} 
Contemporaneamente, a utilização do espaço da rua, a presença freqüente de acrobacias no exercício flaneur sobre rodas, a presença marcante da vestimenta punk, o encontro de motoqueiros e a estética suja no estilo Taxi Driver remetem à lembrança de um ethos não mais prevalente na contemporaneidade de homens limpos, mulheres maquiadas e, acima, uma aura de sucesso. O respeito como forma de socialidade é marca distintiva, o consumo frequente e visível de drogas no espaço não parece oferecer nenhum problema para as relações de contato e, talvez, sejam até uma ponte para o estabelecimento de empatias.

Compreender que o excesso pode ser equilibrado e que contatos sociais podem ser serenos sem nenhuma regulação institucional está em desacordo com a histeria da vida eterna que fantasiamos ser um valor importante (não fume, mas beba cerveja - não corra, mas compre um carro potente). Para a juventude pobre esse é um tema ainda mais dramático, ao invés de trágico, o que seria bem mais adequado. Seus estereótipos fantasmáticos não autorizam sua canalização em eventos festivos, como a atual criminalização do funk deixa transparecer, assim como já havia acontecido com o samba.

Impedido de ser vivido tribalmente e com isso homeopatizar-se, tornando-se inofensivo, trancamos o leão no quintal e sentamos na mesa de jantar. A pretensão de eliminar tudo o que aparenta descontrole desconhece parcela da existência humana que só pode ser controlada se admitida, como a violência, a alteridade, a errância. Nas palavras de Michel Maffesoli, reconhecer o que cabe ao diabo, saber dar-lhe bom uso, para que não sufoque o corpo social ${ }^{33}$.

Inegável a importância da criminologia para a contestação interna e externa do sistema de justiça criminal, bem como a relevância das pesquisas com dados estatísticos sobre o funcionamento do sistema penal e os trabalhos dos realistas de esquerda (outra rotulação que abarca pesquisadores com pensamentos bastante diversos) sobre propostas pragmáticas de redução de danos e prevenção da violência. Sustentar a viabilidade de uma abertura epistemológica transdisciplinar não significa desprestigiar todo o arcabouço teórico construído até aqui, mas partindo destes sugerir novas formas de abordagem que permitam a entrada do cotidiano sem o pressuposto de controlá-lo:

Historicamente os trabalhos fundacionais da criminologia emergiram de abordagens idiossincráticas, impressionistas e 'indisciplinadas' que pouco se assemelham com qualquer tipo de metodologia formalizada (Adler e Adler, 1998). Por exemplo,

\footnotetext{
${ }^{33}$ MAFFESOLI, Michel. A Parte do Diabo. Rio de Janeiro: Record, 2004 p.16.
} 
quando os acadêmicos da Escola de Chicago, nas décadas de 20 e 30, desenvolveram suas pesquisas, o fizeram harmonizando os seus sentimentos e o seu tempo. Frederic Thrasher (1927:XIII, 79), em sua pesquisa de 571 páginas intitulada A Gangue, "realizada num período de aproximadamente sete anos", não apenas apresentou detalhadamente suas impressões sobre "a emocionante vida das gangues de rua", como incluiu suas fotos in situ dos rituais e do cotidiano das gangues juvenis. Décadas mais tarde, pesquisadores vinculados à National Deviancy Conference na Grã-Bretanha (e.g. Young, 1971; Cohen, 1972) e pesquisadores norte-americanos como Howard Becker (1963) e Ned Polsky (1967), desenvolveram pesquisas que se mantêm na base da criminologia e que emergiram não de metodologias preconcebidas, mas do seu estilo de vida marginal e de suas (i)morais predileções ${ }^{34}$.

Contemporaneamente, o acréscimo de práticas e alocuções claramente excludentes em substituição a um decadente discurso disciplinar é tema contínuo de pesquisas sóciocriminológicas. Podemos contestar se em algum momento as instituições de controle adquiriram feições disciplinares ressocializadoras nas periferias do mundo, mas de qualquer forma é nítido que os controles cínicos, camuflados em uma espécie de niilismo atuarial, encorparam nas grandes cidades.

No modelo atuarial, já não se pretende um projeto disciplinar, entendido no sentido foucaultiano como modalidade de poder que garante a docilidade e utilidade dos indivíduos. Foucault já antevia a emergência de técnicas de governamentalidade que se diferenciariam do projeto disciplinar, e se dirigiriam a coletividades consideradas como conjunto de agregados com maior ou menor potencial de risco a ser administrado $^{35}$.

A observação etnográfica do urbano permite o afastamento da versão oficial da realidade produzida pela mídia e pelo Sistema de Justiça Criminal, muitas vezes parceiros na troca de números e pânicos. Documentando as realidades vividas e inspirando-se nessas experiências, a criminologia pode ser apta a desconstruir o discurso totalizante demonizante, bem como sugerir instrumentos baseados em estratégias profanas de combate discursivo, contendo o punitivismo.

Do ponto de vista epistemológico com a adesão as linhas críticas sobre as formas de produção científica de Feyerabend, do ponto de vista metodológico com a incorporação das técnicas de investigação (etnografia e análise de casos) e das categorias de análise (desvio, etiquetamento, subculturas e empreendimentos morais) do labelling aproach, e com o reconhecimento da importância do pensamento crítico pós-moderno - "orientação que, no seu melhor, compartilha

\footnotetext{
${ }^{34}$ FERREL, Jeff. Morte ao Método: uma provocação. Tradução de Salo de Carvalho. Artigo ainda não publicado, cedido pelo tradutor. (Publicado originalmente no Journal of Theoretical and Philosophical Criminology, volume 01, número 01, 2009).

${ }^{35}$ AZEVEDO, Rodrigo Ghiringhelli. Teoria e Prática da Pesquisa Sócio-Criminológica. Rio de Janeiro:2010, p.169.
} 
muito com o anarquismo" - a visão criminológico-cultural fornece multiplicidade de perspectivas prático-teóricas na construção do caleidoscópio interpretativo dos fenômenos contemporâneos crime e desvio ${ }^{36}$.

A criminologia pode aproveitar sua abertura epistemológica para apreender com mais agilidade os discursos não acadêmicos que possam servir como barreira ao pânico moral que legitima grande parte das intervenções estatais autoritárias, ao mesmo tempo em que sugere a valorização de formas não institucionais de resolução de conflitos e formação de discursos emancipatórios.

\begin{abstract}
A superação do homem teórico socrático e do modelo científico dos últimos homens, notadamente no que diz respeito as ciências criminais, pode ser intentada a partir de duas distintas formas de abordagem: intrínseca, ou seja, a partir do âmbito interno das ciências, através da assunção da transdisciplinaridade; extrínseca, a partir da abertura das ciências ao conhecimento profano. Esses movimentos possibilitariam substituir a perspectiva dramática pela trágica, potencializando nas mais distintas formas a vida, e não o conhecimento mesmo ${ }^{37}$.
\end{abstract}

\title{
3.Conclusão
}

As pesquisas jornalísticas, as pesquisas quantitativas, as abordagens generalistas, as visões prescritivas não conseguem dar o multi-sentido das perspectivas emitidas pelas culturas juvenis contemporâneas. Elas desenham constelações móveis, desordenadas, de faces múltiplas. Trata-se de fragmentos e de fraturas cheias de significados líquidos: um sentido fluído alterado é posto em ação por um panorama contextual e metodológico no qual não é mais possível organizar, com tipologias ou tabelas, um suposto objeto da pesquisa.

Produziu-se uma fratura disjuntiva nas narrativas dessas culturas, onde a criação de perspectivas e métodos atípicos pode ser importante. Como refere Salo de Carvalho, nesse quadro, são imprescindíveis as lições de Ruth Gauer no sentido de não renunciar a possibilidade de repensar a organização dos saberes e de conceber novas formas que privilegiem as interações entre os campos científicos, já que a interdisciplinaridade é um processo: uma maneira de apreender a realidade ou uma maneira de encará-la ${ }^{38}$.

\footnotetext{
${ }^{36}$ CARVALHO, Salo. Criminologia Cultural, Complexidade e as Fronteiras de Pesquisa nas Ciências Criminais. in Revista Brasileira de Ciências Criminais, vol. 81, São Paulo, 2009.

${ }^{37}$ CARVALHO, Salo. In: PANDOLFO, Alexandre Costi; SONGHEN, Clarice. Encontros entre Direito e Literatura. Porto Alegre: EDIPUCRS, 2008, p.75.

${ }^{38}$ CARVALHO, Salo. Criminologia Cultural, Complexidade e as Fronteiras de Pesquisa nas Ciências Criminais. in Revista Brasileira de Ciências Criminais, vol. 81, São Paulo, 2009.
} 
O que as diferentes vertentes dos Estudos Culturais têm em comum é que todas elas retiram a prática e conhecimento científicos do âmbito exclusivo da Epistemologia e trazem qualquer discussão sobre essa prática e sobre esse conhecimento para o mundo da vida. $O$ campo dos estudos culturais caracteriza-se por não ser - e não querer ser - um campo homogêneo e disciplinar. Mas não é só isso; os Estudos Culturais não são simplesmente interdisciplinares; eles são frequentemente, como outros têm dito, ativa e agressivamente antidisciplinares $^{39}$.

Isso não é exposto para dizer que as determinações econômicas não sejam importantes, sejam menos importantes que determinações psiquiátricas ou de qualquer outro campo de saber e nem que tudo se equivale, mas para lembrar que as determinações não guardam sempre posição hierarquizada e estável entre $\mathrm{si}^{40}$.

O método etnográfico é desafiado pelos contextos da pós-modernidade, defende Massimo Canevacci. É desafiado tanto na busca quanto na realização. O método deve evitar se tornar uma gaiola que produz e encerra seus sujeitos, organizando-os em objetos puros dos quais extrair regras, leis, previsões, tipologias, prescrições, tratamentos. Por tudo isto, a sugestão de descentralizar o método, multiplicá-lo em seu próprio agir, construí-lo e diferenciá-lo ao longo de narrativas assimétricas: assumir como irredutiveis os sujeitos protagonistas das culturas juvenis ${ }^{41}$.

São as zonas limítrofes, fronteiras, espaços vazios e atravessamentos que mais interessam ao estudo do desvio na pós-modernidade. Reivindica-se, portanto, uma espontaneidade metodológica polifônica que vai de encontro ao rigor excessivamente formalista. O objetivo explícito seria aplicar uma metodologia das diferenças, a fim de acentuar os traços de desordenação das produções juvenis ${ }^{42}$.

A criminologia pode fornecer campo interessante na compreensão e exposição da problemática do desvio, por oferecer uma epistemologia suficientemente aberta e transdisciplinar, necessidade sem a qual a multiplicidade de possibilidades desviantes não tem

\footnotetext{
${ }^{39}$ WORTMANN, Maria Lúcia Castagna; VEIGA-NETO, Alfredo. Estudos culturais da ciência \& educação. Belo Horizonte: Autêntica, 2001, p. 21.

${ }^{40}$ VEIGA-NETO, Alfredo. Caminhos investigativos: novos olhares na pesquisa em educação. Org. de Marisa Vorraber Costa. Porto Alegre: Mediação, 1996, p. 33.

${ }^{41}$ CANEVACCI, Massimo. Culturas Extremas: mutações juvenis nos corpos das metrópoles. Rio de Janeiro: DP\&A, 2005.

${ }^{42}$ CANEVACCI, Massimo. Culturas Extremas: mutações juvenis nos corpos das metrópoles. Rio de Janeiro: DP\&A, 2005.
} 
como ser observada em conjunto, hipótese que acredito ser mais frutífera que o isolamento etnográfico em um único objeto de pesquisa sub, contra ou transcultural, pois o neotribalismo é justamente certa fissura identitária que provoca ajuntamentos coletivos de identidades móveis: personas - a existência como obra de arte ${ }^{43}$.

Da mesma forma que o Brasil é um país racista sem preconceituosos (poucos levantam a mão para defender o preconceito racial), as faculdades de Direito são estranhas construções onde todos legitimam seu conhecimento reforçando a importância de um discurso sem facticidade: O contrato social, a filosofia política liberal, o sujeito de direitos, o equilíbrio de poderes, a contenção do poder punitivo, a ampliação das garantias constitucionais, a proporcionalidade...Não se trata de negar a importância destes conceitos, mas de afirmar que qualquer discurso de sustentação que parta destes dogmas como promessa de Justiça carece de responsabilidade.

Nomear as execuções contínuas, as masmorras contínuas, as prisões ilegais contínuas e a ausência contínua do acesso à justiça como déficit constitucional é absolutamente ilógico. Seria nomear a morte como déficit de vida. O estado de direito precisa ser pinçado pormenorizadamente da realidade da vida para ser demonstrado. O estado de exceção é a vida onde se procura alucinadamente um estado de direito para ser ativado em casos especiais.

A discussão sobre as gerações de direitos e a importância hiperbólica e irreal atribuída ao garantismo penal são temas tão frequentes que ao final da graduação em direito temos quase impressão de que existem. Por vezes ao perceber o absurdo destas afirmações e na tentativa natural de sacralizar nossa formação, atribuímos ao nosso exercício profissional o alcance destes dogmas liberais, como se percebe em descrições como "advocacia militante".

Teríamos, nesta hipótese, um estado de direito deficitário ao qual devíamos doar todas nossas forças para que fosse plenamente alcançado. Como se todo dia ao visitar Josef $\mathrm{K}$, gritássemos algumas palavras inúteis ao porteiro, entregássemos alguns papéis timbrados com palavras bonitas cheias de arroubos de juristas pretensamente emancipatórios, cobrássemos os honorários e voltássemos para casa com a sensação de dever cumprido. Nada como a autolegitimação para a expiação da culpa... Oferecer o cotidiano como pesquisa, no campo das Ciências Criminais, pode apresentar a visualização da realidade absurda sobre a qual os fundamentos do Direito Penal depositam suas realidades inventadas.

${ }^{43}$ DELEUZE, Gilles. Conversações. São Paulo: Editora 34, 1992. p. 116 


\section{Referências}

ALBRECHT, Peter-Alexis. Criminologia: uma fundamentação para o Direito Penal. Rio de Janeiro: Lumen Juris, 2010.

AZEVEDO, Rodrigo Ghiringhelli de. Visões da Sociedade Punitiva: Elementos para uma Sociologia do Controle Penal; in GAUER, Ruth M. Chittó (org.). Sistema Penal e Violência. Rio de Janeiro: Lumen Juris, 2006.

AZEVEDO, Rodrigo Ghiringhelli. Teoria e Prática da Pesquisa Sócio-Criminológica. Rio de Janeiro:2010.

BATISTA, Vera Malaguti. Introdução crítica à criminologia brasileira. Rio de janeiro: Revan, 2011.

BATISTA, Vera Malaguti. Paz Armada. Rio de janeiro; Revan, 2012.

BAUMAN, Zygmunt. Amor líquido: sobre a fragilidade dos laços humanos. Rio de Janeiro: Jorge Zahar, 2004.

BAUMAN, Zygmunt. Em busca da política. Rio de Janeiro: Jorge Zahar, 2000.

BECKER, Howard. Outsiders: estudos de sociologia do desvio. Rio de Janeiro: Zahar, 2008.

CABANES, Robert [et al].Saídas de Emergência. São Paulo: Boitempo, 2011, p.193.

CANEVACCI, Massimo. Culturas Extremas: mutações juvenis nos corpos das metrópoles. Rio de Janeiro: DP\&A, 2005.

CARVALHO, Salo. Criminologia Cultural, Complexidade e as Fronteiras de Pesquisa nas Ciências Criminais. in Revista Brasileira de Ciências Criminais, vol. 81, São Paulo, 2009.

CARVALHO, Salo. In: PANDOLFO, Alexandre Costi; SONGHEN, Clarice. Encontros entre Direito e Literatura. Porto Alegre: EDIPUCRS, 2008.

DaMatta, Roberto. Relativizando. São Paulo: Rocco, 2012.

DELEUZE, Gilles. Conversações. São Paulo: Editora 34, 1992.

DELMAS-MARTY, Mireille. A imprecisão do Direito: do Código penal aos Direitos Humanos. Barueri: Manole, 2005.

ELIAS, Norbert. Os estabelecidos e os outsiders: sociologia das relações de poder a partir de uma pequena comunidade. Rio de Janeiro, Zahar, 2000. 
FERREL, Jeff. Morte ao Método: uma provocação. Tradução de Salo de Carvalho. Artigo ainda não publicado, cedido pelo tradutor. (Publicado originalmente no Journal of Theoretical and Philosophical Criminology, volume 01, número 01, 2009).

GAUER, Ruth M.Chittó. Da Diferença Perigosa ao Perigo da Igualdade. Porto Alegre: Civitas, v.5. n 2. 2005.

KAFKA, Franz. O Processo. São Paulo: Companhia das Letras, 2005.

LEFEBVRE, Henri. O direito à cidade. São Paulo: Centauro, 2001 .

MAFFESOLI, Michel. A Parte do Diabo. Rio de Janeiro: Record, 2004.

MAFFESOLI, Michel. A violência totalitária. Porto Alegre: Sulina, 2001.

MAFFESOLI, Michel. O instante eterno: o retorno do trágico nas sociedades pós-modernas. São Paulo: Zouk, 2003.

MAGNANI, José Guilherme Cantor. Jovens na metrópole. São Paulo: Terceiro Nome, 2007.

MISSE, Michel. Malandros, marginais e vagabundos. A acumulação social da violência no Rio de janeiro. Tese de Doutorado em Sociologia: IUPERJ, Brasil, 1999.

SOARES, Luiz Eduardo [et al].Cabeça de Porco. Rio de Janeiro: Objetiva, 2005.

VEIGA-NETO, Alfredo. Caminhos investigativos: novos olhares na pesquisa em educação. Org. de Marisa Vorraber Costa. Porto Alegre: Mediação, 1996.

VELHO, Gilberto. A utopia urbana: um estudo de antropologia social. Rio de janeiro: Zahar, 2010.

WHYTE, William Foote. Sociedade de esquina: a estrutura social de uma área urbana pobre e degradada. Rio de Janeiro: Jorge Zahar, 2005.

WHYTE, William Foote. Sociedade de esquina: a estrutura social de uma área urbana pobre e degradada. Rio de Janeiro: Jorge Zahar, 2005.

WORTMANN, Maria Lúcia Castagna; VEIGA-NETO, Alfredo. Estudos culturais da ciência \& educação. Belo Horizonte: Autêntica, 2001.

XIBERRAS, Martine. A Sociedade Intoxicada. Lisboa: Piaget, 1989.

XIBERRAS, Martine. As Teorias da Exclusão. Lisboa: Piaget, 1994.

ZAFFARONI, E. Raul; BATISTA,Nilo; ALAGIA, Alejandro; SLOKAR, Alejandro. Direito Penal Brasileiro: Teoria Geral do Direito Penal. Rio de Janeiro: Revan, 2 ed.,2003. 